\title{
Resenhas
}




\section{O Brasil levanta a cabeça?}

João Machado Borges Neto

T ALVEZ a melhor maneira de caracterizar O Brasil e a economia internacional - Recuperação e defesa da autonomia nacional, do economista Paulo Nogueira Batista Jr., seja pela conclusão de sua apresentação. Depois de se referir a um trabalho anterior seu-Da crise internacional à moratória brasileira, de 1988 -, o autor diz que "os valores e as preocupações centrais" dos dois livros "são exatamente os mesmos". E emenda: "Nem poderia ser diferente. Afinal, como dizia Schopenhauer, a maior prova de superficialidade é acreditar que as pessoas mudam" (p.XIX).

Naturalmente, podemos discordar de Schopenhauer e dizer que há pessoas que mudam. De fato, se formos examinar os valores e as preocupações fundamentais de cada um, a mudança não é nada excepcional. Mesmo se restringimos bastante nosso foco, e falamos apenas dos economistas, não há como negar que muitos abandonam completamente hoje os valores abraçados anos atrás. Haverá nisso alguma continuidade mais profunda, oculta por mudanças mais superficiais? Talvez. De qualquer maneira, esse não é o caso do autor: a notável coerência de sua obra não pode ser posta em dúvida.

Assim, O Brasil e a economia internacional representa, sobretudo, uma atualização e um aprofundamento da análise de temas já tratados por Paulo Nogueira Batista Jr. em obras anteriores, iluminados pelas mesmas preocupações centrais e pela defesa dos mesmos valores. Mas traz também por uma novidade importante, que se deve à constatação de que, nos últimos anos, alguma coisa mudou para melhor na América do Sul (e no mundo). E na economia brasileira, no que diz respeito às suas relações internacionais. $\mathrm{O}$ autor examina essas mudanças, bem como seus limites.

O livro divide-se em duas partes e cinco capítulos, além de uma apresentação.

A primeira parte, "Finanças internacionais e a economia brasileira", é subdividida em três capítulos, e "aborda a dimensão cambial e financeira do relacionamento externo da economia brasileira e temas correlatos" (p.XVI). O primeiro capítulo retoma uma visão crítica (e cética) da "globalização" - o autor escreve esse termo sempre entre aspas -, já exposta em trabalhos anteriores. O destaque aqui é a crítica à idéia de "globalização" monetária, especialmente ao argumento de que "a 'globalização', particularmente na sua dimensão financeira, estaria tornando inviáveis ou obsoletas as moedas nacionais na periferia do sistema mundial" (p.9). Quem defende esse ponto de vista diz que os países periféricos estão forçados a optar por alguma forma de dependência monetária (isto é, a adotar alguma forma de dolarização); o autor mostra o equívoco dessa posição, examinando a experiência da América Latina e, em particular, da Argentina e do Brasil. O segundo e o terceiro capítulos comentam o agravamento da dependência do Brasil trazido pelo Plano Real e analisam a relativa melhora da situação desde a adoção da flutuação cambial, em 1999. Destacam a significativa mudança nas contas externas brasileiras desde 2003. Já a permanência da vulnerabilidade externa é enfatizada, e são indicadas medidas neces- 
sárias para enfrentá-la. O terceiro capítulo inclui também um comentário crítico sobre a política do governo Lula nessa área.

A segunda parte do livro analisa as negociações comerciais de que o Brasil participa. O quarto capítulo trata da Alca, "a mais perigosa" dessas negociações. $\mathrm{O}$ quinto trata das negociações comerciais no governo Lula; além de comentar a mudança na estratégia negociadora do Itamaraty na Alca, são estudadas também as negociações entre o Mercosul e a União Européia, as negociações na OMC, e negociações Sul-Sul (especialmente na América Latina).

Como já foi observado antes, o livro tem uma notável continuidade em relação a trabalhos anteriores do autor. A preocupação com a defesa da autonomia econômica nacional brasileira (e de outras economias periféricas), acompanhada pela ênfase em que a "globalização" não diminui em nada sua necessidade, é um eixo de toda a argumentação. A recusa das "modas" do pensamento econômico que vêm dos países centrais (em especial dos Estados Unidos), que camuflam a defesa de interesses estrangeiros com argumentos pseudocientíficos, combinada com um apelo para que pensemos com nossas próprias cabeças, é outra diretriz. E podemos dizer que uma terceira característica da obra é a de se centrar no exame cuidadoso dos fatos, e não na construção de modelos de economias imaginárias (como fazem muitos economistas, especialmente os vinculados à ortodoxia dominante). Aliás, essa postura metodológica é uma das razões, sem dúvida, para o autor se considerar "um solitário [...] que interage pouco com seus colegas de profissão" (p.XVI). Tudo isso faz de $O$ Brasil e a economia internacional uma obra indispensável para quem pretende compreen- der a economia brasileira, os seus problemas, e buscar soluções que viabilizem o desenvolvimento nacional.

Há também uma novidade importante em relação a trabalhos de anos anteriores, o que não é menos relevante. Ela aparece de forma mais clara na apresentação, mas está presente também ao longo do livro, especialmente no terceiro e no quinto capítulos. Trata-se de uma visão razoavelmente otimista sobre a situação do Brasil e da América do Sul. Daí o título da apresentação: "O Brasil levanta a cabeça".

O autor expõe duas ordens de razões para esse (moderado) otimismo. A primeira são mudanças políticas e ideológicas:

As forças que predominaram na década de 1990 sofreram derrotas em vários países da América do Sul e já não reinam incontestes em lugar algum. $\mathrm{O}$ fracasso, às vezes estrepitoso, da maioria dos países que seguiram fielmente as receitas econômicas do chamado Consenso de Washington abalou convicções arraigadas e produziu reviravoltas políticas, não raro dramáticas. (p.IX)

Os países em que os novos tempos se manifestam mais claramente são a Argentina - outrora o país mais alinhado com Washington - e a Venezuela. Mas o autor observa que os ventos de mudança sopravam fortemente também na Bolívia (o que a eleição de Evo Morales viria a confirmar) e, de uma forma mais moderada, no resto da América do Sul. O novo quadro ideológico, na verdade, não se restringe ao nosso continente. "De modo geral, a ideologia da globalização [...] perdeu charme e capacidade de pressão". Isso tanto porque "as assimetrias e desigualdades associadas ao processo de internacionalização tornaram-se mais evidentes" quanto pela proliferação de crises 
cambiais e financeiras que abalaram "a confiança na desregulamentação das economias e na liberalização dos fluxos internacionais de capital". Os movimentos sociais antiglobalização cresceram, e o unilateralismo do governo Bush também contribuiu para o "refluxo dos discursos pró-globalização" (p.X e XI).

$\mathrm{O}$ autor acredita que numa das áreas de atuação do governo Lula - a da política externa e, em particular, das negociações comerciais - esses novos ventos se fizeram sentir. Aí a política do atual governo teria mudado para melhor, com relação à do seu antecessor.

A outra ordem de razões para o moderado otimismo do autor são os progressos recentes da economia brasileira: o controle da inflação, a pequena melhora das finanças públicas ("ainda que à custa de uma carga tributária elevada, investimentos públicos deprimidos e escassez crônica de recursos para as políticas de distribuição de renda e combate à miséria") e, sobretudo, a melhora das contas externas.

Com relação a essa segunda ordem de razões para otimismo, o próprio autor faz muitas qualificações. Além de apontar que os resultados na área externa "não são propriamente mérito nem do governo Lula nem do governo Fernando Henrique" (p.XIII), em toda a primeira parte do livro são enfatizadas as fragilidades que permanecem na economia brasileira e o muito que ainda há por fazer para que ela possa retomar de forma consistente $\mathrm{o}$ caminho do desenvolvimento. Além disso, o livro deixa claro que, ao não implementar políticas como a regulação da conta de capitais, a administração mais rigorosa do perfil do passivo externo do país, e a manutenção de um estoque adequado de reservas internacionais, o governo Lula desperdiçou "a oportunidade proporcionada pelo contexto financeiro externo benigno que predominou em 2003 e 2004" (e podemos acrescentar: também em 2005) (p.66-7). Na verdade, a atuação do governo Lula foi um pouco pior do que isso: além de não tratar da regulação da conta de capitais, por exemplo, ele aprofundou sua liberalização (fato lembrado na p.66). O que cabe discutir, então, é se o otimismo do autor não deveria ser, na questão das mudanças da economia brasileira, um pouco mais moderado e qualificado do que já está.

Além disso, com relação às mudanças políticas e ideológicas na América Latina (e no mundo), e à política internacional do governo Lula (mais especificamente, com relação ao encaminhamento das negociações comerciais, que é o aspecto da política externa abordado no livro), talvez devamos questionar se a avaliação positiva feita pelo autor, ainda que com qualificações, não foi excessiva.

Não há dúvida de que a ideologia da "globalização" e a adesão às idéias conservadoras do Consenso de Washington perderam força. Na América Latina, isso se tem traduzido, de fato, em vitórias eleitorais de "partidos ou coligações moderadamente reformistas" (p.X), ou até mais do que isso, no caso da Venezuela (e, quem sabe, da Bolívia). O autor, contudo, não desconhece que, na maior parte dos casos, há um descompasso entre a rejeição do discurso da "globalização" e do Consenso de Washington - isto é, o discurso neoliberal - pelos eleitores e a prática concreta dos novos governos eleitos. Para muitos deles, o que pode ser dito de positivo é o seguinte:

Ainda que parcialmente imobilizados por restrições financeiras, vulnerabilidades externas ou inibições e inseguranças de outra natureza, esses governos não 
têm condições de seguir a cartilha de Washington com a convicção de seus antecessores. Quando insistem em fazềlo, enfrentam grandes resistências internas, às vezes violentas. (p.X)

Isso é verdade, sem dúvida, mas talvez seja necessário chamar a atenção para o outro lado da questão. Ou seja: no caso de muitos governos latino-americanos a desproporção entre a rejeição das políticas neoliberais pelos eleitores e as mudanças efetivas é enorme. Se é verdade que um governo como o do presidente Lula "não tem condições de seguir a cartilha de Washington com a conviç̧ão de seus antecessores", o que não pode ser esquecido é que ele, no fundamental, ainda que menos convicto (e com muitas diferenciações internas), continua a seguir essa cartilha.

Também podemos fazer uma qualificação quanto à apreciação muito positiva feita pelo autor da estratégia nas negociações comerciais. É preciso reconhecer, naturalmente, que as dificuldades aí são imensas - tanto pelas pressões internacionais quanto pela existência da "quinta coluna" dentro do nosso país, como lembra corretamente o livro. Além disso, não é possível negar que houve mudanças muito significativas em relação à atuação do governo anterior. No entanto, há ambigüidades na estratégia brasileira atual, e não convém subestimar alguns problemas. Por exemplo: o Itamaraty não tem aceitado tratar no âmbito da Alca certos temas francamente desfavoráveis para o Brasil, como serviços, investimentos, compras governamentais e propriedade intelectual, mas aceita tratá-los na OMC. A vantagem disso seria a OMC se constituir num campo mais favorável de negociação, já que divergências entre os países desenvolvidos poderiam ser exploradas, e o Brasil tem interesses comuns com ou- tros grandes países periféricos, como a Índia, a China e a África do Sul (p.139).

Isso pode ser verdade, mas não anula o fato de os países desenvolvidos compartilharem seus interesses, em grande medi$\mathrm{da}$, nas questões mais perigosas, o que faz a assimetria de poder na OMC não diferir tanto da existente na Alca. De fato, muitos estudiosos que acompanham a OMC do ponto de vista dos interesses do Terceiro Mundo têm visto com reservas as posições tomadas pelo Brasil em 2004 e 2005.

Em conclusão: sem negar a importância das mudanças dos últimos anos, inclusive no Brasil, talvez seja exagerado dizer que o país já levantou a cabeça. O que não tira em nada os méritos do livro de Paulo Nogueira Batista Jr. Pelo contrário: ainda que achemos que o autor tenha exagerado no seu otimismo, somos convidados a uma discussão absolutamente necessária: o que é preciso para que nosso país possa realmente se erguer?

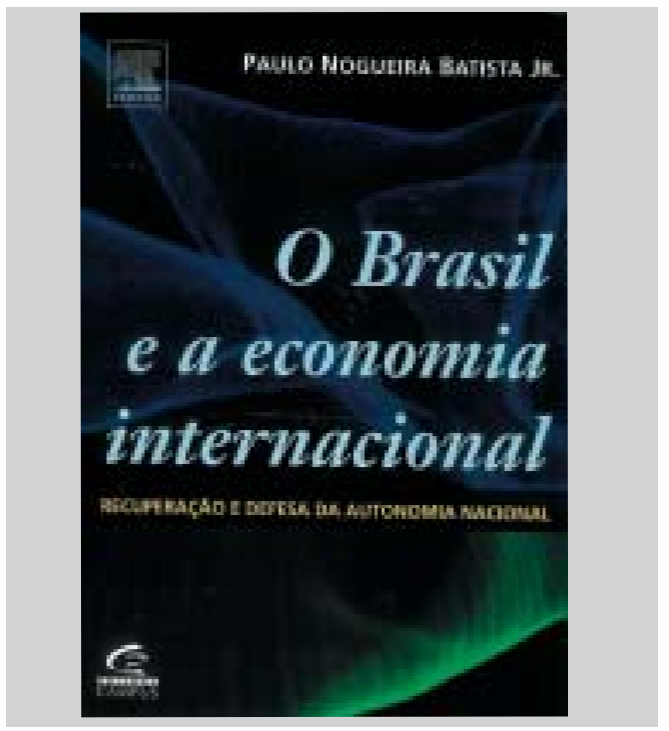

BATISTA JUNIOR, P. N. O Brasil e a economia internacional - Recuperação e defesa da autonomia nacional. Rio de Janeiro: Elsevier, 2005.

João Machado Borges Neto é professor no Departamento de Economia da PUC-SP. 